\title{
Verification of contextual information (V3) in the System for Analysis of Validity in Evaluation (SAVE).
}

DOI: $10.46932 /$ sfjdv2n2-206

Received in: March 1st, 2021

Accepted in: May 30th, 2021

\section{Jorge Jiménez Serrano}

Behavior \& Law Research Foundation, Madrid, Spain:

Email: jjimenez@behaviorandlaw.com

\section{VERIFICATION, CORRESPONDENCE OR CONTEXT}

In SAVE (López, et al, 2018), Verification (V3) aims to verify the authenticity of something; in our case we try to add data or observable facts, better if they are objective, on the elements proposed in the previous phases, to consolidate or discard them. This is the field that corresponds to evidence in law, for which there is a specific sub-discipline, Probática (Sabaté, 2012).

\section{FROM THE CRIMINALISTIC APPROACH TO THE RECONSTRUCTION OF THE FACTS}

Such evidence, following the criminalistic approach, arises from so called Locard's exchange principle, according to which victim and perpetrator, in their criminal interaction, exchange physical material that remains in the possession of the other (Locard, 1934). In other words, the criminal, in the development of his criminal behavior, comes into contact and interacts with material elements at a given temporal and spatial moment, leaving traces or traces that can be identified, collected, and analyzed. This is precisely the work of criminalists who process crime scenes, collecting material evidence such as fingerprints, fibers, biological remains (saliva, blood, semen...). In turn, police investigators, through their investigations, try to collect associative evidence that shows their relationship with the investigated facts, thus being able to identify places, documents, people, or situations.

All this scientific and operational work is intended to follow the Principle of Reconstruction, which relates the facts with all the evidence to recreate the criminal act with descriptive explanations and graphic demonstrations of the set of behaviors, maneuvers and dynamics carried out in the investigated (Montiel, 2007).

From the scientific analysis of all the evidence, evidence is established in an attempt to reconstruct the criminal act. Some of these pieces of evidence can be:

- Sequence evidence: They allow us to establish a chronology of the occurrence and sequence of an event.

- Location evidence: It allows us to establish where an object or person was at a given time.

- Contact evidence: This allows us to identify the connection between people, objects, or places. 
- Action evidence: This allows us to identify behaviors and events that occurred during an event.

With this reconstruction based on scientific methodology and supported by verifiable objective elements, the investigation is able to approach the knowledge of the historical truth of the event regarding its form, manner, or mechanics of production, being this an irreplaceable support element so that the judge can finally elevate the evidence provided to proof.

This criminal investigation approach can be extrapolated to the evaluation and verification of any occurrence or event since the objective pursued is the same, to compare if there is coherence between what a subject declares about a fact or what the a priori indications suggest that it could have happened, with external traces or vestiges that this event has left.

\section{SOURCES OF EVIDENCE}

This evidence, by definition, must be objective and contrasted elements or information that can be verified and show a certain degree of certainty. They can be obtained from various sources depending on the type and circumstances of the event being evaluated. For example, in a medical-pericial context this evidence can be obtained through a complementary exploration (Domínguez et al., 2018). In other types of cases, the location of a person in a particular place at a particular time can be evidenced through the recording of a security camera or the GPS position of their cell phone. Nowadays, it is increasingly common to collect fingerprints from computer systems and processes. Precisely this IT context allows access to a large amount of information that can be used for this verification work. We refer to the use of open sources, also called OSINT (Open-Source Intelligence), which allows us to access public information that can be collected from the Internet: social networks, metadata, articles...).

\section{CONCLUSIONS}

The SAVE Metaprotocol is mainly formed by behavioral analysis methodologies, which sometimes involves providing conclusions or decisions from the psychological level that usually have less support and legal power than those probative elements based on material evidence.

Precisely, by introducing this phase V3, we also provide the external coherence facilitated by the material, objective, and verifiable elements that accompany the investigated fact. These elements are worked following the approach of criminalistics and criminal investigation.

Keywords: Behavioral analysis, means of proof, Locard exchange principle, verification, deception detection. 


\section{REFERENCES}

Domínguez-Muñoz, A, De la Fuente, J. L., Gómez, A. M., García, P., López M. J. and López, R. (2018). SAVE-System for Validity Analysis in the Expert Medical Evaluation. In XII Jornadas de Valoración del Daño Corporal. Medical-practical aspects. (pp.245-260) Madrid: Fundación Mapfre.

López, R. M., Domínguez-Muñoz, A., Grau, M., Juárez, A., Jiménez, J., \& Garrido, M. J. (2018). SAVE metaprotocol for behavior analysis. An integrative proposal. In E. Arias, J. Sanmarco, \& X. Camplá (Eds.), XI International Congress of Legal and Forensic Psychology. (pp. 528-541). Granada: Spanish Society of Legal and Forensic Psychology.

Montiel, J. (2007). The scientific method and criminalistics. In Criminalistics 2 (pp. 17-29). Mexico: Limusa

Locard E. (1934). Manual de técnica policíaca (1st edition). Barcelona: José Montesó.

Sabaté, L. M. (2012). Probática: Why not Sherlock Holmes? Diario La Ley, (7947), 1. 